Short communication

\title{
The effect of sporulation medium on Alicyclobacillus acidoterrestris guaiacol production in apple juice
}

\author{
Celenk Molva*, Ayse Handan Baysal \\ Department of Food Engineering, Izmir Institute of Technology, Urla, 35430, Izmir, Turkey
}

\section{A R T I C L E I N F O}

\section{Article history:}

Received 9 October 2015

Received in revised form

18 January 2016

Accepted 29 January 2016

Available online 3 February 2016

\section{Keywords:}

Sporulation medium

Juice spoilage

Guaiacol

Vanillin

Vanillic acid

Chemical compounds studied in this article:

Guaiacol (PubChem CID:460)

Vanillin (PubChem CID:1183)

Vanillic acid (PubChem CID:8468)

\begin{abstract}
A B S T R A C T
The present study evaluated the effect of sporulation medium on guaiacol formation from vanillin and vanillic acid by Alicyclobacillus acidoterrestris DSM 3922 in the reconstituted apple juice ( $\mathrm{pH} 3.82$, ${ }^{\circ}$ Brix 11.3). For sporulation, potato dextrose agar and Bacillus acidoterrestris agar were used. After heatactivation, spores were turned into vegetative cells and inoculated into juice samples to a final concentration of $10^{3}$ or $10^{5} \mathrm{CFU} / \mathrm{mL}$. Samples were incubated at $37^{\circ} \mathrm{C}$ for $264 \mathrm{~h}$ and guaiacol concentration was determined using peroxidase enzyme colourimetric assay. Based on the results, the conversion of vanillic acid into guaiacol was faster than that of vanillin among both cell suspensions. Also, there were no significant differences among any of the samples inoculated into apple juice spiked with vanillin at the end of the incubation period $(P>0.05)$. In the case of vanillic acid, the guaiacol concentrations were significantly different among cells activated from spores produced on PDA and BATA $(P<0.05)$. The obtained results suggested that type of sporulation medium composition may affect the guaiacol concentration depending on inoculum level and type of precursor present in the apple juice.
\end{abstract}

(c) 2016 Elsevier Ltd. All rights reserved.

\section{Introduction}

Alicyclobacillus spp. are aerobic, Gram-positive, endosporeforming, non-pathogenic, thermophilic microorganisms isolated mainly from soil and hot springs (Gobbi et al., 2010). Some species such as Alicyclobacillus acidoterrestris, Alicyclobacillus acidophilus, Alicyclobacillus pomorum, Alicyclobacillus hesperidum, Alicyclobacillus herbarius, Alicyclobacillus cycloheptanicus, and Alicyclobacillus acidocaldarius have the ability to produce taint compounds associated with spoilage. Among them, A. acidoterrestris is the primarily species responsible for spoilage incidents (Smit, Cameron, Venter, \& Witthuhn, 2011). Their endospores have been shown to survive pasteurization applied to fruit juices and acidic products (Vieira, Teixeira, Silva, Gaspar, \& Silva, 2002).

Due to their acidophilic behaviour, surviving spores can germinate and increase in products to cell concentrations high enough to produce off-flavour compounds such as guaiacol (2methoxyphenol), 2,6-dibromophenol, and 2-methoxyphenol.

\footnotetext{
* Corresponding author.

E-mail address: molvacelenk@gmail.com (C. Molva).
}

Guaiacol is the predominant taint metabolite of A. acidoterrestris (Chang \& Kang, 2004; Gocmen, Elston, Williams, Parish, \& Rouseff, 2005). It is formed from vanillin and vanillic acid and can be detected by smell in fruit juices at $2 \mu \mathrm{g} / \mathrm{L}$ (Orr, Shewfelt, Huang, Tefera, \& Beuchat, 2000; Smit et al., 2011). The detection of guaiacol can be performed by sensory (Concina et al., 2010), analytical (Bahçeci \& Acar, 2007; Bahçeci, Gökmen, \& Acar, 2005; Gocmen et al., 2005) or spectrophotometric methods (Bahçeci \& Acar, 2007; Bahçeci et al., 2005).

During juice processing, manufacturers should identify the factors on the guaiacol formation to prevent the spoilage of their products by $A$. acidoterrestris. Cell concentration, incubation temperature, heat shock treatment, growth medium, type of beverages, headspace/oxygen availability are known to influence the guaiacol amount (Smit et al., 2011). Recent studies on A. acidoterrestris focus especially on the effects of preservatives (Cai et al., 2015) and specificity of Alicyclobacillus spp. isolates (Chang, Park, \& Kang, 2015) for guaiacol formation. To our knowledge, there was no study about the effect of sporulation medium on guaiacol amount produced by A. acidoterrestris. Therefore, the objective of this study was to determine the effect of sporulation medium composition on the guaiacol production by $A$. acidoterrestris DSM 3922 in 
reconstituted apple juice using peroxidase enzyme colourimetric assay (PECA).

\section{Material and methods}

\subsection{Chemicals}

Vanillin and vanillic acid were purchased from Sigma-Aldrich Company (St. Louis, MO, USA). Stock solutions of vanillin and vanillic acid were prepared by dissolving in $50 \%(\mathrm{v} / \mathrm{v})$ ethanol. All solutions were filter sterilized $(0.22 \mu \mathrm{m}$ pore size, Millipore), and prepared freshly before analysis.

\subsection{Test organism}

A. acidoterrestris DSM 3922 was kindly provided by Karl Poralla (Deutsche Sammlung von Mikroorganismen und Zellkulturen's collection, Braunschweig, Germany). For sporulation, potato dextrose agar [PDA, Difco BD, (potato extract $4.0 \mathrm{~g} / \mathrm{L}$; dextrose $20.0 \mathrm{~g} / \mathrm{L}$ and agar-agar $15.0 \mathrm{~g} / \mathrm{L}, \mathrm{pH} 3.50 \pm 0.1)$ and Bacillus acidoterrestris agar [BATA, Merck (yeast extract $2.0 \mathrm{~g} / \mathrm{L}, \mathrm{D}(+)$ glucose $5.0 \mathrm{~g} / \mathrm{L}, \mathrm{CaCl}_{2} .2 \mathrm{H}_{2} \mathrm{O} 0.25 \mathrm{~g} / \mathrm{L}, \mathrm{MgSO}_{4} .7 \mathrm{H}_{2} \mathrm{O} 0.5 \mathrm{~g} / \mathrm{L},\left(\mathrm{NH}_{4}\right)_{2} \mathrm{SO}_{4} 0.2 \mathrm{~g} / \mathrm{L}$, $\mathrm{KH}_{2} \mathrm{PO}_{4} 3.0 \mathrm{~g} / \mathrm{L}$, agar-agar $18 \mathrm{~g} / \mathrm{L}$ and $1 \mathrm{~mL}$ trace element solution containing $\mathrm{CaCl}_{2} .2 \mathrm{H}_{2} \mathrm{O} 0.66 \mathrm{~g} / \mathrm{L}, \mathrm{ZnSO}_{4} .7 \mathrm{H}_{2} \mathrm{O} 0.18 \mathrm{~g} / \mathrm{L}, \mathrm{CuSO}_{4} 0.16 \mathrm{~g} /$ $\mathrm{L}, \mathrm{MnSO}_{4} .7 \mathrm{H}_{2} \mathrm{O} 0.15 \mathrm{~g} / \mathrm{L}, \mathrm{CoCl}_{2} 0.18 \mathrm{~g} / \mathrm{L}, \mathrm{H}_{3} \mathrm{BO}_{3} 0.1 \mathrm{~g} / \mathrm{L}, \mathrm{Na}_{2} \mathrm{MoO}_{4} .2$ $\mathrm{H}_{2} \mathrm{O} 0.3 \mathrm{~g} / \mathrm{L}, \mathrm{pH} 4.0 \pm 0.2$ )] were used. Spore suspensions were prepared based on the protocol as previously described (Molva \& Baysal, 2014).

\subsection{Apple juice}

Concentrated apple juice (ASYA Fruit Juice and Food Ind. Inc., Isparta, Turkey) was reconstituted to $11.30 \pm 0.1{ }^{\circ}$ Brix (pH $3.82 \pm 0.01$ ) by a refractometer (Mettler Toledo, USA). Diluted juice samples were tested for the presence of Alicyclobacillus spp. by membrane filtration method (Molva \& Baysal, 2014).

\subsection{Detection of guaiacol in the apple juice}

After heat activation at $80{ }^{\circ} \mathrm{C}$ for $10 \mathrm{~min}$ in a water bath and cooling on ice, the spore suspension was centrifuged at $16,000 \times g$ for $5 \mathrm{~min}$. Then, the pellet was dissolved in $1 \mathrm{~mL}$ apple juice and inoculated into $20 \mathrm{~mL}$ apple juice containing $100 \mathrm{mg} / \mathrm{L}$ vanillin or vanillic acid to a final cell concentration of $10^{3}$ or $10^{5} \mathrm{CFU} / \mathrm{mL}$. After inoculation, the samples were divided into $1 \mathrm{~mL}$ portions and transferred into $2 \mathrm{~mL}$ sterile eppendorf tubes. Then, the tubes were incubated at $37{ }^{\circ} \mathrm{C}$. Guaiacol concentration was determined at certain time intervals $(24,48,72,144,168$ and 264 h) by the PECA (Witthuhn, van der Merwe, Venter, \& Cameron, 2012). Apple juice samples containing vanillin and vanillic acid without inoculum were used as controls.

\subsection{Statistical analysis}

Data $(n=3)$ were expressed as means \pm standard deviations (Microsoft Excel 2003, Microsoft corp., USA). The Tukey-Kramer test was used to compare the means of treated groups $(P<0.05)$ (Minitab 17, Minitab Inc., UK).

\section{Results and discussion}

In the present study, the guaiacol production ability of A. acidoterrestris DSM 3922 was determined in the reconstituted apple juice $\left(\mathrm{pH} \mathrm{3.82,}{ }^{\circ}\right.$ Brix 11.3$)$ spiked with vanillin and vanillic acid during storage at $37{ }^{\circ} \mathrm{C}$. The set of vanillin and vanillic acid concentration (100 mg/L) was based on a previous study in which the use of high concentrations $(1000 \mathrm{mg} / \mathrm{L})$ was found to cause a colour change that might give false positive results with PECA (Witthuhn,van der Merwe, Venter, \& Cameron, 2012). Only vegetative cells are responsible for the production of taint compounds (Smit et al., 2011). Therefore, spore suspensions obtained from two different sporulation medium (PDA and BATA) were encouraged to turn into vegetative forms by heat-activation $\left(80^{\circ} \mathrm{C} / 10 \mathrm{~min}\right)$ and then inoculated into juice samples containing guaiacol precursor.

PECA is easy and rapid, and indicates similar sensitivity compared to HPLC but the guaiacol concentrations below $10 \mathrm{mg} / \mathrm{L}$ cannot be determined exactly (Bahçeci \& Acar, 2007). At the low inoculum level $\left(10^{3} \mathrm{CFU} / \mathrm{mL}\right)$, the guaiacol concentration was below the detection limit in the apple juice with vanillin until $168 \mathrm{~h}$ (Fig. 1a). The cells activated from spores produced on PDA and BATA yielded 30.19 and $29.27 \mathrm{mg} / \mathrm{L}$, respectively at the end of the incubation period (Fig. 1a). And, there was no statistical difference between the guaiacol amount produced by samples recovered from PDA and BATA in the apple juice with vanillin after $264 \mathrm{~h}(P>0.05)$. The cell concentration might be to low produce guaiacol in the presence of vanillin during the incubation period. Bahçeci et al. (2005) concluded that $A$. acidoterrestris started to produce guaiacol from vanillin if the cell concentration exceeded the critical level of $10^{4} \mathrm{CFU} / \mathrm{mL}$. When the vanillic acid was used as precursor (Fig. 1b), the concentration was always above the detection limit of guaiacol. The levels were found as 59.37 and $56.07 \mathrm{mg} / \mathrm{L}$ for samples from PDA and BATA, respectively after 48 h. As seen in Fig. 1b, significant differences were observed between the samples supplemented with vanillic acid among cells from both medium after $264 \mathrm{~h}(P<0.05)$. Witthuhn et al. (2012) reported that the metabolic conversion of vanillic acid to guaiacol was faster than that vanillin in Bacillus acidoterrestris broth. Similar to this finding, the conversion of vanillic acid to guaiacol was found faster than vanillin added in apple juice. The increased rate may be due to the fact that vanillic acid is the direct precursor of guaiacol (Huang, Dostal, \& Rosazza, 1993).

At the high inoculum level $\left(10^{5} \mathrm{CFU} / \mathrm{mL}\right)$, the cells activated from spores produced on PDA and BATA yielded 30.14 and $33.22 \mathrm{mg} / \mathrm{L}$ guaiacol in the apple juice supplemented with vanillin after 48 and 72 h, respectively (Fig. 2a). In another study (Bahçeci et al., 2005), the formation of guaicol from vanillin was determined using HPLC. These researchers reported that the concentration of guaiacol produced in apple juice was found to be dependent on the amount of vanillin. They found that guaiacol production started immediately in apple juice inoculated with $100 \mathrm{mg} / \mathrm{L}$ vanillin and $10^{5} \mathrm{CFU} /$ $\mathrm{mL}$ of $A$. acidoterrestris DSM 2498 spores at $46{ }^{\circ} \mathrm{C}$. The amount of guaiacol increased linearly during $96 \mathrm{~h}$ of incubation, and reached to a plateau. At the end of the incubation period ( $240 \mathrm{~h})$, they found that the final concentration was $59.18 \mathrm{mg} / \mathrm{L}$ guiacol in the juice sample. Similar to previous findings, the amount of guaiacol increased with time, then approached almost a plateau and finally started to decrease when vanillic acid was used as precursor (Figs. 1b and 2b). The differences between the guaiacol concentrations obtained in this study and other studies might be due to the differences among strains, incubation temperature, or types and amounts of precursors added juice samples. In case of vanillic acid added into apple juice, the highest concentration was obtained after $24 \mathrm{~h}$ among cells obtained from spores grown on PDA (Fig. 2b). On the other hand, cells formed from spores on BATA yielded $57.45 \mathrm{mg} / \mathrm{L}$ after $48 \mathrm{~h}$. As mentioned earlier, differences in guaiacol amount between cells from both sample types were statistically significant in the apple juice spiked with only vanillic acid after $264 \mathrm{~h}$ at the high inoculum level $(P<0.05)$. 

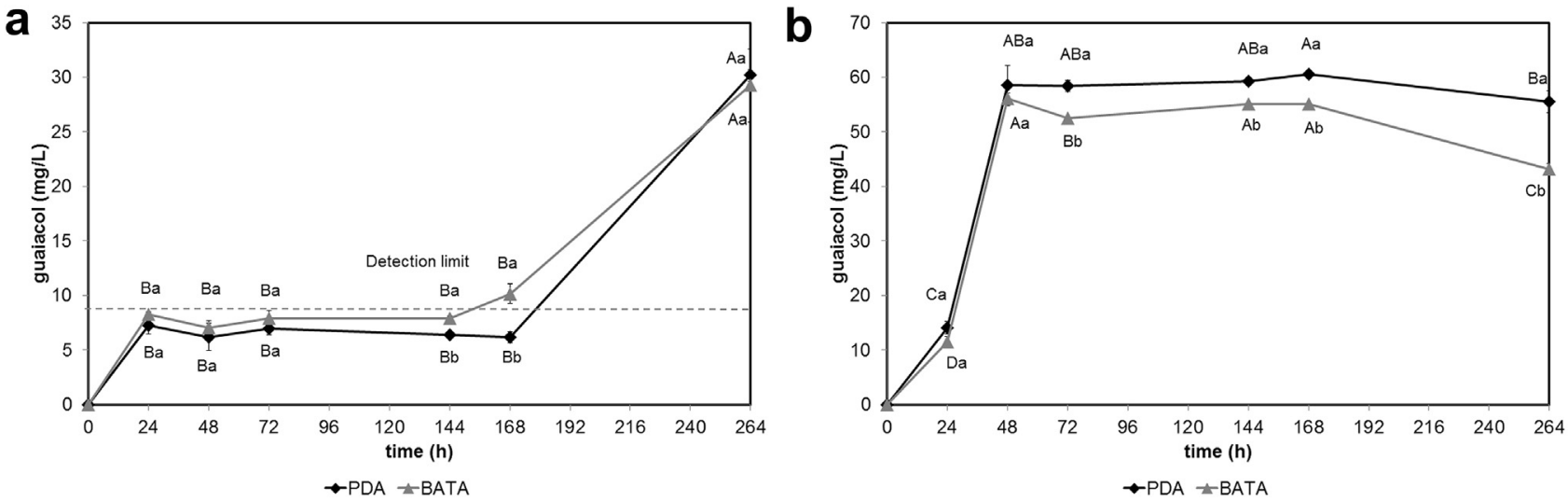

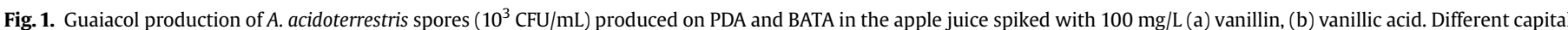

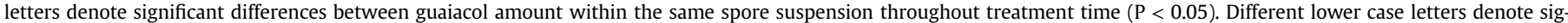
nificant differences among both spore suspensions within the same incubation time $(P<0.05)$. Each bar represents the mean \pm standard deviation of three replicates $(n=3)$.
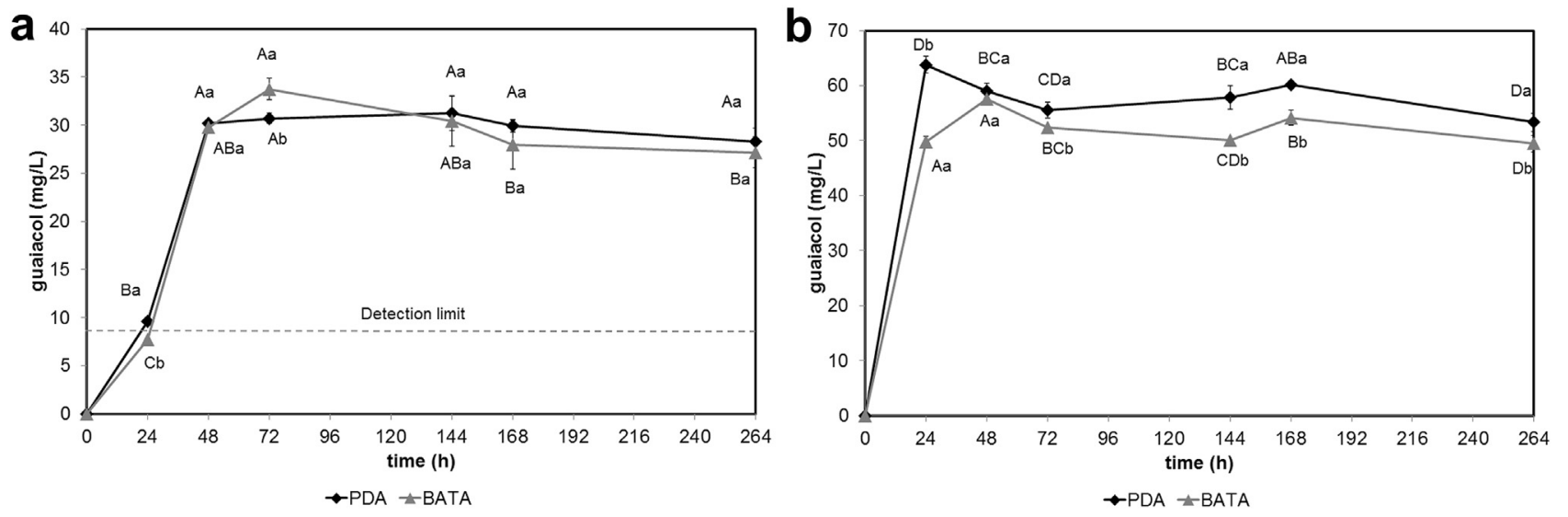

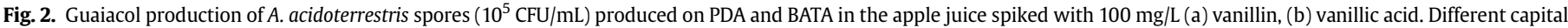

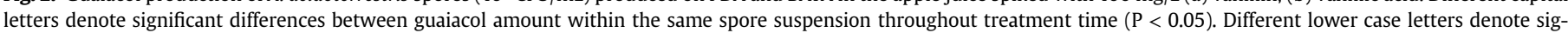

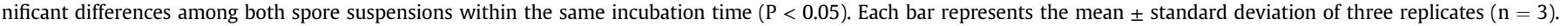

\section{Conclusions}

A. acidoterrestris spores can survive pasteurization during juice processing, and then germinate into vegetative cells leading to spoilage due to production of off-flavour compounds. Among them, guaiacol is the major compound related to spoilage resulting in high economic losses for juice industry. We observed a significant difference in guaiacol concentrations in the apple juice with vanillic acid in the presence of cells activated from $10^{3}$ or $10^{5} \mathrm{CFU} / \mathrm{mL}$ of initial spore levels from $72 \mathrm{~h}$ to the end of incubation. Since spore properties and germination efficiency are affected by the differences in environmental conditions such as sporulation temperature, nutritional and chemical composition, and $\mathrm{pH}$ of the sporulation medium (Eijlander, Abee, \& Kuipers, 2011), it can be concluded that the differences in guaiacol amounts may be related to spore properties from different sporulation medium activated to turn into vegetative cells. Further studies are needed to study the effect of sporulation medium composition on guaiacol formation by A. acidoterrestris.

\section{Conflict of interest}

There is no conflict of interest.

\section{References}

*Bahçeci, K. S., \& Acar, J. (2007). Determination of guaiacol produced by Alicyclobacillus acidoterrestris in apple juice by using HPLC and spectrophotometric methods, and mathematical modeling of guaiacol production. European Food Research and Technology, 225, 873-878.

*Bahçeci, S. K., Gökmen, V., \& Acar, J. (2005). Formation of guaiacol from vanillin by Alicyclobacillus acidoterrestris in apple juice: a model study. European Food Research and Technology, 220, 196-199.

Cai, R., Yuan, Y., Wang, Z., Guo, C., Liu, B., Pan, C., et al. (2015). Effects of preservatives on Alicyclobacillus acidoterrestris growth and guaiacol production. International Journal of Food Microbiology, 20, 145-150.

*Chang, S. S., \& Kang, D. H. (2004). Alicyclobacillus spp. in the fruit juice industry: history, characteristics, and current isolation/detection procedures. Critical Reviews in Microbiology, 30, 55-74.

Chang, S., Park, S.-H., \& Kang, D.-H. (2015). Effect of extrinsic factors on the production of guaiacol by Alicyclobacillus spp. Journal of Food Protection, 4, $831-835$.

Concina, I., Bornšek, M., Baccelliere, S., Falasconi, M., Gobbi, E., \& Sberveglieri, C. (2010). Alicyclobacillus spp.: detection in soft drinks by electronic nose. Food Research International, 43, 2108-2114.

Eijlander, R. T. Abee, T. \& Kuipers, O. P. (2011). Bacterial spores in food: how phenotypic variability complicates prediction of spore properties and bacterial behavior. Current Opinion in Biotechnology, 22, 180-186.

Gobbi, E., Falasconi, M., Concina, I., Mantero, G., Bianchi, F., Mattarozzi, M., et al.

\footnotetext{
${ }^{*}$ The selected key references include different sensory, analytical and spectrophometric methods used for the detection of guaiacol produced by A. acidoterrestris.
} 
(2010). Electronic nose and Alicyclobacillus spp. spoilage of fruit juices: an emerging diagnostic tool. Food Control, 21, 1374-1382.

*Gocmen, D., Elston, A., Williams, T., Parish, M., \& Rouseff, R. L. (2005). Identification of medicinal off-flavours generated by Alicyclobacillus species in orange juice using GC-olfactometry and GC-MS. Letters in Applied Microbiology, 40, 172-177.

Huang, Z., Dostal, L., \& Rosazza, J. P. (1993). Mechanisms of ferulic acid conversions to vanillic acid and guaiacol by Rhodotorula rubra. Journal of Biological Chemistry, $268,23954-23958$.

Molva, C., \& Baysal, A. H. (2014). Effect of sporulation medium on wet-heat resistance and structure of Alicyclobacillus acidoterrestris DSM 3922-type strain spores and modeling of the inactivation kinetics in apple juice. Internationa Journal of Food Microbiology, 189, 82-88.

Orr, R. V., Shewfelt, T. L., Huang, C. J., Tefera, S., \& Beuchat, L. R. (2000). Detection of guaiacol produced by Alicyclobacillus acidoterrestris in apple juice by sensory and chromatographic analyses, and comparison with spore and vegetative cell populations. Journal of Food Protectection, 63, 1517-1522.

Smit, Y., Cameron, M., Venter, P., \& Witthuhn, R. C. (2011). Alicyclobacillus spoilage and isolation-A review. Food Microbiology, 28, 331-349.

Vieira, M. C., Teixeira, A. A., Silva, F. M., Gaspar, N., \& Silva, C. L. M. (2002). Alicyclobacillus acidoterrestris spores as a target for Cupuaçu (Theobroma grandiflorum) nectar thermal processing: kinetic parameters and experimental methods. International Journal of Food Microbiology, 77, 71-81.

*Witthuhn, R. C., van der Merwe, E., Venter, P., \& Cameron, M. (2012). Guaiacol production from ferulic acid, vanillin and vanillic acid by Alicyclobacillus acidoterrestris. International Journal of Food Microbiology, 157, 113-117. 